\title{
Accurate Quantification of Polycyclic Aromatic Hydrocarbons in Environmental Samples Using Deuterium-labeled Compounds as Internal Standards
}

\author{
Nobuyasu Itoh, ${ }^{\dagger}$ Masahiko Numata, Yoshie AOYagi, and Takashi YARITA \\ National Metrology Institute of Japan (NMIJ), National Institute of Advanced Industrial Science and \\ Technology (AIST), 1-1-1 Umezono, Tsukuba, Ibaraki 305-8563, Japan
}

\begin{abstract}
For the accurate quantification of polycyclic aromatic hydrocarbons (PAHs) in environmental samples by isotope-dilution mass spectrometry (IDMS) and gas chromatography-mass spectrometry (GC-MS), we used deuterium-labeled PAHs (D-PAHs) as internal standards for $\mu \mathrm{g} \mathrm{g}^{-1}$-level certified reference materials and corresponding calibration solutions. Although pressurized liquid extraction (PLE) causes significant biases in the analytical results for $\mathrm{ng}^{-1}$-level samples $(2.4-15 \%)$, biases in the analytical results by PLE $\left(190^{\circ} \mathrm{C}, 20 \mathrm{MPa}, 2\right.$ cycles $)$ were small $(<2.3 \%)$ and negligible for $\mu \mathrm{g} \mathrm{g}^{-1}$-level samples when expanded uncertainty (coverage factor $k=2$ ) was considered.
\end{abstract}

(Received April 4, 2008; Accepted July 28, 2008; Published September 10, 2008)

\section{Introduction}

Polycyclic aromatic hydrocarbons (PAHs) are formed through incomplete combustion in anthropogenic processes, such as burning of fossil fuels, and through natural processes, such as forest fires. ${ }^{1}$ Because PAHs are transported for long distances, they are found in most environmental samples throughout the world. $^{2-4}$ Because PAHs are carcinogenic, ${ }^{5}$ it is necessary to monitor their levels in the environment.

Isotope-dilution mass spectrometry (IDMS) is used for the accurate quantification of target compounds in complex samples. ${ }^{6,7}$ Although both ${ }^{13} \mathrm{C}$ - and deuterium-labeled PAHs ${ }^{13} \mathrm{C}-\mathrm{PAHs}$ and D-PAHs, respectively) have been used as internal standards, ${ }^{8-13}$ D-PAHs at trace levels (ng $\mathrm{mL}^{-1}$ level) show different behaviors from native PAHs in the injection liner of gas chromatography (GC). ${ }^{14}$ Since different behaviors were also observed in calibration solutions, the analytical results can differ by 1.9 to $13 \% .^{14}$ However, D-PAHs are preferable for routine analyses, especially for contaminated samples at the $\mu \mathrm{g} \mathrm{g}^{-1}$-level, which need large amounts of internal standards, since ${ }^{13} \mathrm{C}-\mathrm{PAHs}$ are more expensive.

Pressurized liquid extraction (PLE) was developed for the extraction of organic compounds from solid samples. Because PLE not only has at least as good an extraction efficiency as Soxhlet extraction, but is also faster and consumes less solvent, ${ }^{15-18}$ it is widely used for routine work. On the other hand, native PAHs and D-PAHs show different behaviors during the PLE process of samples at $\mathrm{ng} \mathrm{g}^{-1} .^{19}$ The bias occurring during the PLE process is larger than that in the injection liner, and differences are greater at lower temperature $(2.4-4.3 \%$ at $150^{\circ} \mathrm{C}$ and $6.3-15 \%$ at $\left.40^{\circ} \mathrm{C}\right) .{ }^{19}$ Although the different behaviors do not cause any bias in the injection liner of GC using $\mu \mathrm{g} \mathrm{mL} \mathrm{m}^{-1}$-level samples, ${ }^{14}$ bias during the PLE process of

$\dagger$ To whom correspondence should be addressed.

E-mail: nobuyasu-itoh@aist.go.jp $\mu \mathrm{g} \mathrm{g}^{-1}$-level samples had not been examined. Thus, we examined the bias due to D-PAHs as internal standards during the PLE process of $\mu \mathrm{g} \mathrm{g}^{-1}$-level samples.

In this study, we tested D-PAHs as internal standards for accurate quantification using certified reference materials at the $\mu \mathrm{g} \mathrm{g}^{-1}$-level and corresponding calibration solutions. We evaluated the significances of differences in the analytical results of PLE in consideration of their uncertainty.

\section{Experimental}

Materials and reagents

Phenanthrene (Phe) was obtained from Supelco (Bellefonte, PA, USA). Fluoranthene (Flu), benz $[a]$ anthracene $(\mathrm{BaA})$, and benzo $[a]$ pyrene $(\mathrm{BaP})$ were obtained from Tokyo Chemical Industry (Tokyo, Japan). Benzo[ghi]perylene (BghiP) was obtained from AccuStandard (New Haven, CT, USA). DPAHs - $\left[{ }^{2} \mathrm{H}_{10}\right]$ phenanthrene $\left(\mathrm{D}_{10}-\mathrm{Phe}, 98 \%\right.$ isotope purity), $\left[{ }^{2} \mathrm{H}_{10}\right]$ fluoranthene $\left(\mathrm{D}_{10}-\mathrm{Flu}, 98 \%\right), \quad\left[{ }^{2} \mathrm{H}_{12}\right]$ benz $[a]$ anthracene $\left(\mathrm{D}_{12}-\mathrm{BaA}, 98 \%\right)$, $\left[{ }^{2} \mathrm{H}_{12}\right]$ benzo[a]pyrene $\left(\mathrm{D}_{12}-\mathrm{BaP}, 98 \%\right)$, and $\left[{ }^{2} \mathrm{H}_{12}\right]$ benzo[ghi]perylene ( $\mathrm{D}_{12}$-BghiP, 98\%)—dissolved in isooctane were obtained from Cambridge Isotope Laboratories (Andover, MA, USA). GC-MS revealed no native PAHs in the D-PAH solutions. Hexane, toluene, and anhydrous $\mathrm{Na}_{2} \mathrm{SO}_{4}$ (Kanto Chemical, Tokyo, Japan) were of pesticide- or PCBanalysis grade. Activated copper powder was obtained from Kishida Chemical (Osaka, Japan). Certified reference materials (CRMs) used in this study were SRM1944 (New York/New Jersey Waterway Sediment) and SRM1649a (Urban Dust) from the US National Institute of Standards and Technology (NIST; Gaithersburg, MA, USA).

\section{Preparation of calibration and surrogate solutions}

Each native PAH was diluted with toluene, and the resulting solutions were combined. D-PAH solutions were similarly prepared. Part of the D-PAH mixture was diluted further with 
toluene to form a surrogate solution, and the remainder was added to the native PAH mixture to obtain two calibration solutions (A: $7.8 \mu \mathrm{g}$ g-toluene ${ }^{-1}$ Phe, $10.7 \mu \mathrm{g}$ g-toluene ${ }^{-1} \mathrm{Flu}$, $3.6 \mu \mathrm{g}$ g-toluene ${ }^{-1} \mathrm{BaA}, 4.0 \mu \mathrm{g}$ g-toluene ${ }^{-1} \mathrm{BaP}$, and $7.2 \mu \mathrm{g}$ gtoluene ${ }^{-1}$ BghiP. B: $16.0 \mu \mathrm{g}$ g-toluene ${ }^{-1}$ Phe, $16.3 \mu \mathrm{g} \mathrm{g}$-toluene $^{-1}$ Flu, 7.0 $\mu \mathrm{g}$ g-toluene ${ }^{-1} \mathrm{BaA}, 5.9 \mu \mathrm{g}$ g-toluene ${ }^{-1} \mathrm{BaP}$, and $5.8 \mu \mathrm{g}$ g-toluene ${ }^{-1}$ BghiP).

\section{Pressurized liquid extraction}

The NIST standard reference material (SRM) samples were extracted in a Dionex ASE 200 Accelerated Solvent Extractor (Dionex, Sunnyvale, CA, USA) equipped with 11-mL stainlesssteel extraction cells containing a cellulose filter at the bottom. After the addition of $0.15 \mathrm{~g}$ of SRM1649a or $3 \mathrm{~g}$ of SRM1944, a few grams of anhydrous $\mathrm{Na}_{2} \mathrm{SO}_{4}$ were added and the mixture was thoroughly shaken. Then, the surrogate solution was added, followed by sufficient anhydrous $\mathrm{Na}_{2} \mathrm{SO}_{4}$ to fill the vacant space in the cell. The cell was kept overnight at room temperature before extraction to completely remove any toluene originating from the surrogate solution.

The samples were extracted with toluene under static conditions $\left(190^{\circ} \mathrm{C}, 20 \mathrm{MPa}\right)$ for $10 \mathrm{~min}$ (two cycles). Elemental sulfur was removed by a treatment with activated copper, and the extracts were filtered through a PTFE filter $(0.1 \mu \mathrm{m}$ pore $)$ under a vacuum. Each filtered sample was concentrated to approximately $1 \mathrm{~mL}$ in a rotary evaporator and a stream of nitrogen gas. Blank samples were prepared in the same way, except for the sediment sample and the surrogate solution.

The PLE-treated calibration solutions were prepared using intact calibration solutions to examine changes in the ratio of native PAHs to D-PAHs during the PLE process. The PLE process was performed in the same way $\left(190^{\circ} \mathrm{C}, 20 \mathrm{MPa}, 10\right.$ min, 2 cycles) as the blank samples, except for the addition of intact calibration solutions.

\section{Clean-up procedure}

The concentrated extract was cleaned up with a silica-gel solid-phase extraction (SPE) cartridge $(500 \mathrm{mg} / 3 \mathrm{~mL}$ Isolute Silica, International Sorbent Technology, Hengoed, Wales) with a RapidTrace automation system (Zymark, Hopkinton, MA, USA). PAHs were eluted with $6 \mathrm{~mL}$ of hexane. The hexane was evaporated and replaced by toluene (100 $\mu \mathrm{L}$ for SRM1649a and $3 \mathrm{~mL}$ for SRM1944).

\section{GC-MS analysis}

GC-MS analysis was carried out with an Agilent 6890/5975 GC-MS system (Agilent Technologies, Palo Alto, CA, USA) equipped with a DB-17MS capillary column $(30 \mathrm{~m} \times 0.25 \mathrm{~mm}$ i.d. $\times 0.25 \mu \mathrm{m}$ film thickness; J \& W Scientific, Folsom, CA, USA). The GC was operated in the splitless mode, and $1-\mu \mathrm{L}$ portions of the extracts were injected via an auto-sampler. Both the injection liner and the transfer line were maintained at $300^{\circ} \mathrm{C}$. The oven temperature was programmed to rise from $50^{\circ} \mathrm{C}$ ( 2 min hold) to $240^{\circ} \mathrm{C}$ at a rate of $10^{\circ} \mathrm{C} \mathrm{min}^{-1}$, and then at $1.25^{\circ} \mathrm{C} \mathrm{min}^{-1}$ up to $300^{\circ} \mathrm{C}$ (10 min hold). Helium was used as

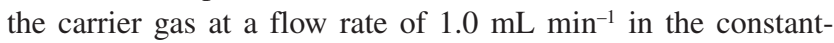
flow mode. The electron impact ionization energy was $70 \mathrm{eV}$. The data for quantification were obtained in the selected ion monitoring mode. The ions selected for each PAH $(\mathrm{m} / \mathrm{z})$ were as follows: Phe (178.1, 176.1), Flu (202.1, 200.1), BaA (228.1, 226.1), BaP (252.1, 250.1$),$ BghiP (276.2, 277.2), $\mathrm{D}_{10-\mathrm{Phe}}$ (188.2, 189.2), $\mathrm{D}_{10}$-Flu (212.2, 211.2), $\mathrm{D}_{12}$-BaA (240.2, 239.2), $\mathrm{D}_{12}$-BaP $(264.2,265.2)$, and $\mathrm{D}_{12}$-BghiP $(288.2,289.2)$. The underlined ions were used for quantification. (a)

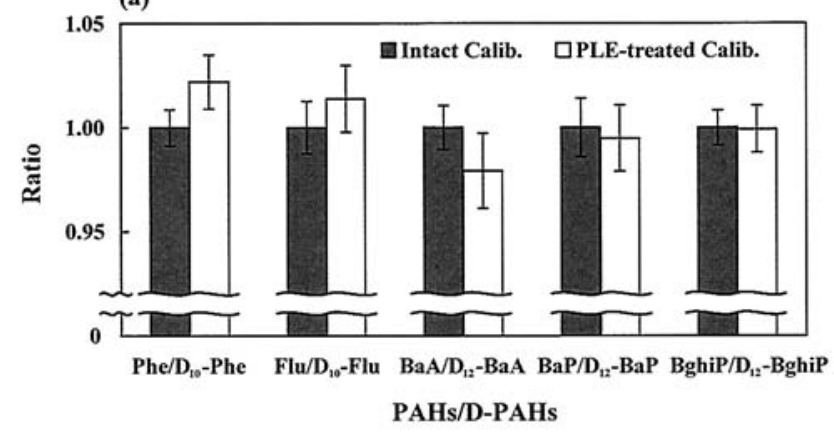

(b)

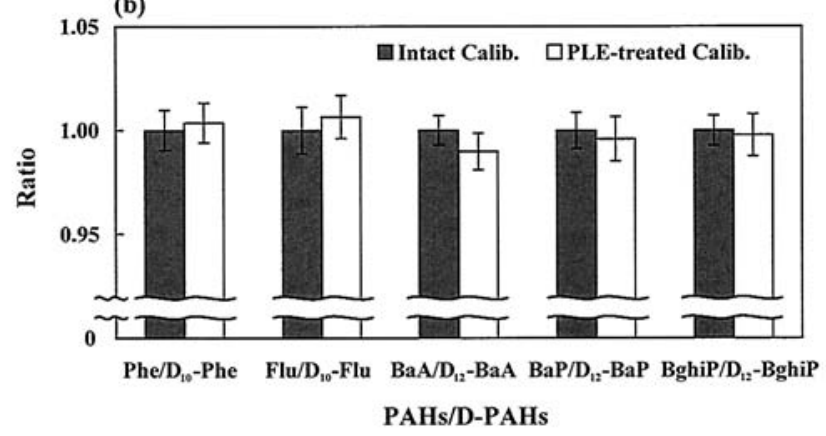

Fig. 1 Ratios of native PAH to D-PAH in intact and PLE-treated calibration solutions A (a) and B (b). Error bars indicate the standard deviation $(n=4)$. Intact Calib., calibration solution without PLE process; PLE-treated Calib., calibration solution with PLE process.

\section{Results and Discussion}

Effect of the PLE process on native PAH/D-PAH ratios in the calibration solutions

The PLE process is known to change the ratio of native PAHs to D-PAHs, even in the calibration solutions at trace level (ng $\mathrm{mL}^{-1}$ level), owing to their slightly different stabilities at 40 and $150^{\circ} \mathrm{C}$ under $15 \mathrm{MPa}^{19}$ On the other hand, after a previous study, ${ }^{19}$ it was confirmed that a harsher condition $\left(190^{\circ} \mathrm{C}, 20\right.$ $\mathrm{MPa})$ can introduce higher analytical results attributed to more effective extraction of native PAHs using the same sediment sample $(+22 \%$ for $\mathrm{Phe},+12 \%$ for $\mathrm{Flu},+7 \%$ for $\mathrm{BaA},+14 \%$ for $\mathrm{BaP}$, and $+16 \%$ for BghiP; details will be shown in elsewhere), although PLE $\left(150^{\circ} \mathrm{C}, 15 \mathrm{MPa}\right)$ can introduce higher analytical results relative to other extraction techniques, such as Soxhlet and microwave-assisted extractions. ${ }^{18}$ Thus, the PLE condition $\left(190^{\circ} \mathrm{C}, 20 \mathrm{MPa}\right)$ was used in this study, since the most effective condition of PLE should be applied to not only the samples, but also the examination of biases during the PLE process.

The ratio of native PAHs to D-PAHs in the intact (without PLE process) and the PLE-treated (with PLE process) calibration solutions was compared at first. Figure 1 shows the changes in the native PAH/D-PAH ratios in the intact and PLEtreated calibration solutions. Theoretically, the ratio of the native PAHs to D-PAHs in the intact and the PLE-treated calibration solutions should be the same, since each PLE-treated calibration solution was prepared from each corresponding intact calibration solution. Actually, however, the ratio was not the same between the intact and PLE-treated calibration solutions. The effects of PLE were the same on both solutions: the ratio increased for Phe and Flu, and decreased for $\mathrm{BaA}, \mathrm{BaP}$, and BghiP. However, the changes were within $2.2 \%$, and were not significant $(P>0.05)$. Moreover, these differences are 
(a)

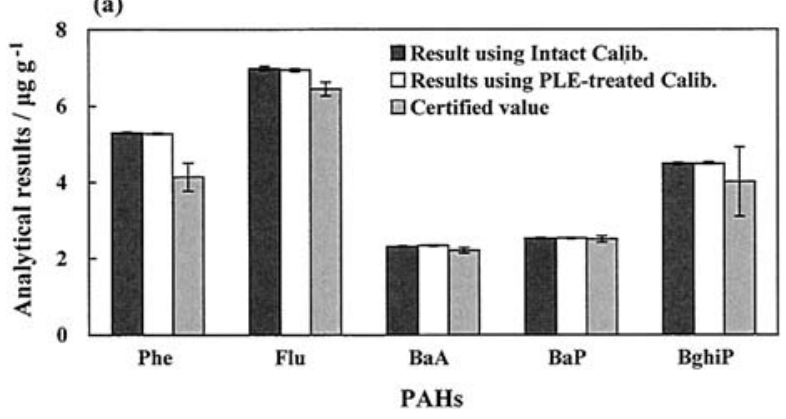

(b)

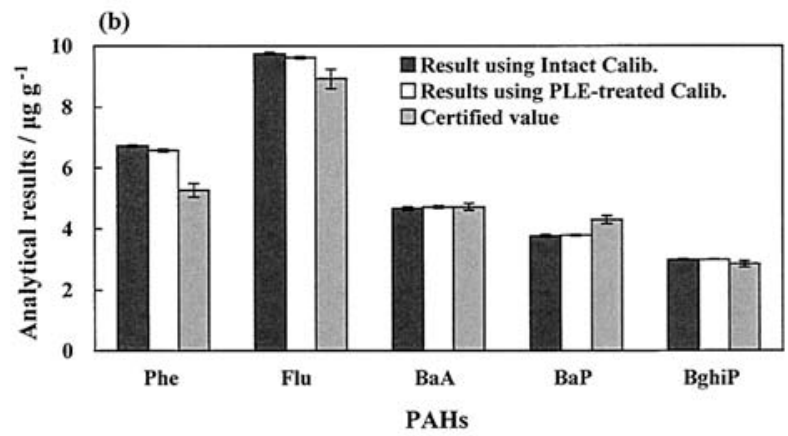

Fig. 2 Analytical results of SRM1649a (a) and SRM1944 (b) obtained by using intact and PLE-treated calibration solutions, and certified values. The error bars of the analytical results indicate the standard deviation $(n=3)$, and those of the certified values indicate the expanded uncertainty (95\% confidence interval). Result using Intact Calib., analytical result obtained using an intact calibration solution; Result using PLE-treated Calib., analytical result obtained using a PLE-treated calibration solution.

smaller than those obtained at lower extraction temperatures $\left(6.3-15 \%\right.$ at $40^{\circ} \mathrm{C}$ and $2.4-4.3 \%$ at $\left.150^{\circ} \mathrm{C}\right)$ at ng g-1evels. ${ }^{19}$ These results suggest that differences in the ratios were suppressed by harsher extraction conditions $\left(190^{\circ} \mathrm{C}, 20 \mathrm{MPa}\right)$ and/or by higher concentrations of PAHs in the calibration solutions ( $\mu \mathrm{g} \mathrm{mL}^{-1}$ level). The bias observed in the GC injection liner was significantly suppressed when higher concentrations of PAHs in the calibration solution ( $\mu \mathrm{g} \mathrm{mL}^{-1}$ level) were used at the same temperature $\left(300^{\circ} \mathrm{C}\right) .^{14}$ Thus, we consider that the smaller differences in the ratio are also due to the higher concentrations, rather than to the harsher conditions of PLE.

\section{Quantification of PAHs in SRMs}

The values of the target compounds in the CRMs are obtained by several different analytical tests and have a 95\% confidence interval. $^{20}$ This allows CRMs to be used to validate analytical procedures. The NIST SRMs are widely used because they have been well characterized by both NIST and other researchers. ${ }^{20}$ Thus, to validate our analytical results, we quantified the five target PAHs in SRM1944 and SRM1649a.

Figure 2 shows the analytical results obtained by using intact and PLE-treated calibration solutions as well as the certified values of the SRMs. Phe, Flu, and BaA showed small, but significant $(P<0.05)$ differences in the analytical results obtained with intact and PLE-treated calibration solutions for both SRM1649a and SRM1944 (0.4-2.3\%). Since all factors were the same, except for the calibration solutions (intact or PLE-treated), the differences between Figs. 1 and 2 (whether significant or not) are partly attributable to changes in the GCMS responses during analysis, such as drift or contamination of the injection liner.
The results of both Phe and Flu are higher (Phe by $\sim 26 \%$ and Flu by $\sim 9 \%$ ) than the certified values of the SRMs obtained by Soxhlet extraction and PLE at $100^{\circ} \mathrm{C}^{21,22}$ Harsher extraction conditions of PLE, especially for temperature, can introduce higher analytical results, as mentioned above. Phe and Flu were higher (by $26 \%$ ) in both SRMs, even though the PAHs were quantified independently (in SRM1649a by calibration solution A and in SRM1944 by calibration solution B). Moreover, Schantz also reported that the result of Phe obtained at $200^{\circ} \mathrm{C}$ was $20 \%$ higher than that obtained at $100^{\circ} \mathrm{C}$ using SRM1650b (diesel particulate matter). ${ }^{23}$ Thus, we consider that our higher results of Phe and Flu are due to extraction at higher temperature.

\section{Estimation of uncertainty}

To evaluate the effect of the PLE process on the biases in analytical results, we first estimated the uncertainty of the results by the following equation:

$$
C_{\text {anal }}=\frac{F_{\text {prep(sample) }}\left(R_{\text {sample }}-R_{\text {blank }}\right) M_{\text {cal }} C_{\text {cal }} M_{\text {spike(sample) }} F_{\text {spike(sample) }} F_{\text {dil(surogate) }}}{M_{\text {sample }} F_{\text {moist }} M_{\text {spikec(cal) }}},
$$

where $C_{\text {anal }}\left(\mu \mathrm{gg}\right.$-sample $\left.{ }^{-1}\right)$ is the concentration of native PAH in the sample (dry-mass basis), $F_{\text {prep(sample) }}$ is efficiency of sample preparation introduced to evaluate the reproducibility, $R_{\text {sample }}$ is the peak area ratio of native PAH to D-PAH in the extract relative to that in the calibration solution, $R_{\text {blank }}$ is the peak area ratio of native PAH to D-PAH in the blank solution relative to that in the calibration solution, $M_{\text {cal }}(\mathrm{mg})$ is the weight of the standard solution of native PAH used to prepare the calibration solution, $C_{\text {cal }}\left(\mu \mathrm{g}\right.$ g-toluene $\left.{ }^{-1}\right)$ is the concentration of PAH in the calibration solution, $M_{\text {spike(sample) }}(\mathrm{mg})$ is the weight of the surrogate solution added to the sample, $F_{\text {spike(sample) }}$ corrects for addition of the surrogate solution, $F_{\text {dil(surrogate) }}$ is the dilution of the sample by the surrogate solution, $M_{\text {sample }}(\mathrm{mg})$ is the weight of the sample taken for analysis, $F_{\text {moist }}$ corrects for the moisture content in the sample, and $M_{\text {spike(cal) }}(\mathrm{mg})$ is the weight of the undiluted surrogate solution used for preparing the calibration solution.

The relative standard uncertainty $\left(u\left(x_{\mathrm{i}}\right) / x_{\mathrm{i}}\right)$ of each factor is summarized in Tables 1 and 2 . The combined standard uncertainty $\left(u_{\mathrm{c}}\right)$ was estimated with Eq. $(2)$, which was obtained from partial differentials of Eq. (1):

$$
u_{\mathrm{c}}=\sqrt{\sum_{\mathrm{i}=1}^{\mathrm{n}}\left\{\frac{\partial C_{\text {anal }}}{\partial x_{\mathrm{i}}} \times u\left(x_{\mathrm{i}}\right)\right\}^{2}}
$$

Although the relative standard uncertainty of $R_{\text {blank }}$ is commonly large for both SRMs $\left(1.8 \times 10^{-2}-1.8 \times 10^{-1}\right)$, its contribution to $u_{\mathrm{c}}$ is small. The relative standard uncertainty of the other factor in Tables 1 and 2 is commonly less than $1 \times 10^{-2}$, so $u_{\mathrm{c}} / C_{\text {anal }}$ of all PAHs in both SRMs is commonly less than $2 \%$.

To evaluate the significance of the differences in the analytical results by the PLE process, including the uncertainty, we evaluated them with

$$
E_{\mathrm{n}}=\frac{\left|C_{\text {Intact }}-C_{\mathrm{PLE}}\right|}{\sqrt{U_{\text {Intact }^{2}+U_{\mathrm{PLE}^{2}}^{2}}}}
$$

where $C_{\text {Intact }}\left(\mu \mathrm{g}\right.$ g-sample $\left.{ }^{-1}\right)$ is the analytical result obtained using an intact calibration solution, $C_{\mathrm{PLE}}\left(\mu \mathrm{g}\right.$ g-sample $\left.{ }^{-1}\right)$ is the analytical result obtained using a PLE-treated calibration solution, $U_{\text {Intact }}$ is the expanded uncertainty (coverage factor $k=$ 2) of $C_{\text {Intact }}$, and $U_{\text {PLE }}$ is the expanded uncertainty $(k=2)$ of $C_{\text {PLE. }}$. By this evaluation, the difference is not significant when $E_{\mathrm{n}} \leq 1$. 
Table 1 Estimation of the uncertainty for the concentrations of PAHs in SRM1649a

\begin{tabular}{|c|c|c|c|c|c|c|c|}
\hline & & & Phe & Flu & $\mathrm{BaA}$ & $\mathrm{BaP}$ & BghiP \\
\hline \multirow[t]{12}{*}{$u\left(x_{\mathrm{i}}\right) / x_{\mathrm{i}}^{\mathrm{a}}$} & Parameter $\left(x_{\mathrm{i}}\right)$ & $F_{\text {prep(sample) }}$ & $1.6 \times 10^{-3}$ & $3.5 \times 10^{-3}$ & $2.4 \times 10^{-3}$ & $2.3 \times 10^{-3}$ & $2.9 \times 10^{-3}$ \\
\hline & & $R_{\text {sample }}$ & $1.6 \times 10^{-3}$ & $4.9 \times 10^{-3}$ & $2.2 \times 10^{-3}$ & $1.4 \times 10^{-3}$ & $3.9 \times 10^{-3}$ \\
\hline & & & $\left(2.1 \times 10^{-3}\right)$ & $\left(2.4 \times 10^{-3}\right)$ & $\left(1.5 \times 10^{-3}\right)$ & $\left(1.6 \times 10^{-3}\right)$ & $\left(3.3 \times 10^{-3}\right)$ \\
\hline & & $R_{\text {blank }}$ & $1.8 \times 10^{-2}$ & $3.4 \times 10^{-2}$ & $4.1 \times 10^{-2}$ & $2.0 \times 10^{-2}$ & $4.7 \times 10^{-2}$ \\
\hline & & $M_{\mathrm{cal}}$ & $1.0 \times 10^{-3}$ & $4.3 \times 10^{-4}$ & $7.7 \times 10^{-4}$ & $5.9 \times 10^{-4}$ & $3.7 \times 10^{-4}$ \\
\hline & & $C_{\text {cal }}$ & $8.3 \times 10^{-3}$ & $8.3 \times 10^{-3}$ & $8.3 \times 10^{-3}$ & $8.3 \times 10^{-3}$ & $8.3 \times 10^{-3}$ \\
\hline & & $M_{\text {spike(sample) }}$ & $1.3 \times 10^{-4}$ & $1.3 \times 10^{-4}$ & $1.3 \times 10^{-4}$ & $1.3 \times 10^{-4}$ & $1.3 \times 10^{-4}$ \\
\hline & & $F_{\text {dil(surrogate) }}$ & $5.5 \times 10^{-3}$ & $5.5 \times 10^{-3}$ & $5.5 \times 10^{-3}$ & $5.5 \times 10^{-3}$ & $5.5 \times 10^{-3}$ \\
\hline & & $M_{\text {spike(sample) }}$ & $7.9 \times 10^{-4}$ & $7.9 \times 10^{-4}$ & $7.9 \times 10^{-4}$ & $7.9 \times 10^{-4}$ & $7.9 \times 10^{-4}$ \\
\hline & & $M_{\text {sample }}$ & $7.1 \times 10^{-4}$ & $7.1 \times 10^{-4}$ & $7.1 \times 10^{-4}$ & $7.1 \times 10^{-4}$ & $7.1 \times 10^{-4}$ \\
\hline & & $F_{\text {moist }}$ & $5.9 \times 10^{-4}$ & $5.9 \times 10^{-4}$ & $5.9 \times 10^{-4}$ & $5.9 \times 10^{-4}$ & $5.9 \times 10^{-4}$ \\
\hline & & $M_{\text {spike(cal) }}$ & $5.5 \times 10^{-3}$ & $5.5 \times 10^{-3}$ & $5.5 \times 10^{-3}$ & $5.5 \times 10^{-3}$ & $5.5 \times 10^{-3}$ \\
\hline \multicolumn{3}{|c|}{$C_{\text {anal }} / \mu g^{-1 b}$} & 5.39 & 7.12 & 2.34 & 2.57 & 4.61 \\
\hline \multicolumn{3}{|c|}{$u_{\mathrm{c}} / \mu \mathrm{g} \mathrm{g}^{-1}$} & 0.06 & 0.09 & 0.03 & 0.03 & 0.06 \\
\hline
\end{tabular}

Values in the parentheses are obtained using PLE calibration solution. a. Relative standard uncertainty. b. Calculated concentration.

Table 2 Estimation of the uncertainty for the concentrations of PAHs in SRM1944

\begin{tabular}{|c|c|c|c|c|c|c|c|}
\hline & & & Phe & Flu & $\mathrm{BaA}$ & $\mathrm{BaP}$ & BghiP \\
\hline \multirow[t]{11}{*}{$u\left(x_{\mathrm{i}}\right) / x_{\mathrm{i}}^{\mathrm{a}}$} & Parameter $\left(x_{\mathrm{i}}\right)$ & $F_{\text {prep(sample) }}$ & $2.5 \times 10^{-3}$ & $2.0 \times 10^{-3}$ & $2.9 \times 10^{-3}$ & $3.6 \times 10^{-3}$ & $1.8 \times 10^{-3}$ \\
\hline & & $R_{\text {sample }}$ & $3.2 \times 10^{-3}$ & $1.2 \times 10^{-3}$ & $1.2 \times 10^{-2}$ & $5.6 \times 10^{-3}$ & $1.9 \times 10^{-3}$ \\
\hline & & $R_{\text {blank }}$ & $1.8 \times 10^{-1}$ & $1.4 \times 10^{-1}$ & $4.0 \times 10^{-2}$ & $1.0 \times 10^{-1}$ & $1.0 \times 10^{-1}$ \\
\hline & & $M_{\mathrm{cal}}$ & $1.0 \times 10^{-3}$ & $4.3 \times 10^{-4}$ & $7.7 \times 10^{-4}$ & $5.9 \times 10^{-4}$ & $3.7 \times 10^{-4}$ \\
\hline & & $C_{\text {cal }}$ & $8.3 \times 10^{-3}$ & $8.3 \times 10^{-3}$ & $8.3 \times 10^{-3}$ & $8.3 \times 10^{-3}$ & $8.3 \times 10^{-3}$ \\
\hline & & $M_{\text {spike(sample) }}$ & $1.2 \times 10^{-3}$ & $1.2 \times 10^{-3}$ & $1.2 \times 10^{-3}$ & $1.2 \times 10^{-3}$ & $1.2 \times 10^{-3}$ \\
\hline & & $F_{\text {dil(surrogate) }}$ & $5.5 \times 10^{-3}$ & $5.5 \times 10^{-3}$ & $5.5 \times 10^{-3}$ & $5.5 \times 10^{-3}$ & $5.5 \times 10^{-3}$ \\
\hline & & $M_{\text {spike(sample) }}$ & $7.9 \times 10^{-4}$ & $7.9 \times 10^{-4}$ & $7.9 \times 10^{-4}$ & $7.9 \times 10^{-4}$ & $7.9 \times 10^{-4}$ \\
\hline & & $M_{\text {sample }}$ & $3.0 \times 10^{-5}$ & $3.0 \times 10^{-5}$ & $3.0 \times 10^{-5}$ & $3.0 \times 10^{-5}$ & $3.0 \times 10^{-5}$ \\
\hline & & $F_{\text {moist }}$ & $2.0 \times 10^{-4}$ & $2.0 \times 10^{-4}$ & $2.0 \times 10^{-4}$ & $2.0 \times 10^{-4}$ & $2.0 \times 10^{-4}$ \\
\hline & & $M_{\text {spike(cal) }}$ & $5.5 \times 10^{-3}$ & $5.5 \times 10^{-3}$ & $5.5 \times 10^{-3}$ & $5.5 \times 10^{-3}$ & $5.5 \times 10^{-3}$ \\
\hline \multicolumn{3}{|c|}{$C_{\text {anal }} / \mu g g^{-1 b}$} & 7.33 & 10.6 & 5.08 & 4.07 & 3.25 \\
\hline \multicolumn{3}{|c|}{$u_{\mathrm{c}} / \mu \mathrm{g} \mathrm{g}^{-1}$} & 0.09 & 0.12 & 0.09 & 0.05 & 0.04 \\
\hline
\end{tabular}

a. Relative standard uncertainty. b. Calculated concentration.

Table $3 \quad E_{\mathrm{n}}$ values of PAHs obtained by intact and PLE-treated calibration solutions

\begin{tabular}{lcc}
\hline & SRM1649a & SRM1944 \\
\hline Phe & 0.13 & 0.59 \\
Flu & 0.17 & 0.38 \\
BaA & 0.29 & 0.18 \\
BaP & 0.11 & 0.13 \\
BghiP & 0.07 & 0.02 \\
\hline
\end{tabular}

Table 3 summarizes the $E_{\mathrm{n}}$ values of the analytical results obtained by intact and PLE-treated calibration solutions. The $E_{\mathrm{n}}$ values of all PAHs in both SRMs ranged from 0.02 to 0.6. Thus, the biases in the $\mathrm{ng} \mathrm{g}^{-1}$-level samples introduced by PLE are not significant for the $\mu \mathrm{g} \mathrm{g}^{-1}$-level samples. ${ }^{19}$ Therefore, the PLE process of the calibration solution used for accurate

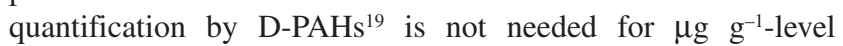
samples, even when D-PAHs are used as internal standards.

\section{Conclusions}

We examined how PLE affects the analytical results when DPAHs are used as internal standards for IDMS. When $\mu \mathrm{g} \mathrm{g}^{-1}$. level samples and calibration solutions containing corresponding concentrations were used, D-PAHs did not introduce significant differences in the results of the five PAHs examined. Since changes in the native PAH/D-PAH ratios in the injection liner are also small $(<2 \%)$ and not significant, we conclude that D-PAHs can be used as internal standards for accurate quantification by IDMS of $\mu \mathrm{g} \mathrm{g}^{-1}$-level samples.

\section{References}

1. B. J. Finlayson-Pitts and J. N. Pitts Jr., "Chemistry of the Upper and Lower Atmosphere: Theory, Experiments, and Applications", 2000, Academic Press, London, 969.

2. P. Masclet, V. Hoyau, J. L. Jaffrezo, and H. Cachier, Atmos. Environ., 2000, 34, 3195.

3. C. A. Menzie, B. B. Potocki, and J. Santodonato, Environ. Sci. Technol., 1992, 26, 1278.

4. N. Ohkouchi, K. Kawamura, and H. Kawahata, Environ. Sci. Technol., 1999, 33, 3086.

5. A. Luch, "The Carcinogenetic Effects of Polycyclic Aromatic Hydrocarbons", 2004, Imperial College Press, London, 489.

6. T. J. Quinn, Metrologia, 1997, 34, 61.

7. P. Ellerbe, S. Meiselman, L. T. Sniegoski, M. J. Welch, and 
V. E. White, Anal. Chem., 1989, 61, 1718.

8. R. Luniewski, B. Kanabe, L. Nasri, P. Hubber, L. Au, and P. Yang, J. Air Waste Manage. Assoc., 1998, 48, 1085.

9. E. Perraudin, H. Budzinski, and E. Villenave, Anal. Bioanal. Chem., 2005, 383, 122.

10. O. Bercaru, F. Ulberth, H. Emons, and C. Vandecasteele, Anal. Bioanal. Chem., 2006, 384, 1207.

11. A. Filipkowska, L. Lubecki, and G. Kowalewska, Anal. Chim. Acta, 2005, 547, 243.

12. W. Jira, Eur. Food Res. Technol., 2004, 218, 208.

13. A. R. Boden and E. J. Reiner, Polycyclic Aromat. Compd., 2004, 24, 309.

14. N. Itoh, M. Numata, Y. Aoyagi, and T. Yarita, J. Chromatogr., A, 2006, 1134, 246.

15. L. Ramos, E. M. Kristenson, and U. A. T. Brinkman, J. Chromatogr., A, 2002, 975, 3.

16. S. Lundstedt, B. van Bavel, P. Haglund, M. Tysklind, and L.
Öberg, J. Chromatogr., A, 2000, 883, 151 .

17. P. Popp, P. Keil, M. Moder, A. Paschke, and U. Thuss, J. Chromatogr., A, 1997, 774, 203.

18. N. Itoh, M. Numata, Y. Aoyagi, and T. Yarita, Anal. Chim. Acta, 2008, 612, 44.

19. N. Itoh, M. Numata, Y. Aoyagi, and T. Yarita, J. Chromatogr., A, 2007, 1138, 26.

20. S. A. Wise, D. L. Poster, J. R. Kucklick, J. M. Keller, S. S. VanderPol, L. C. Sander, and M. M. Schantz, Anal. Bioanal. Chem., 2006, 386, 1153.

21. NIST, "Certificate of Analysis. SRM 1944: New York/New Jersey Waterway Sediment", National Institute of Standards and Technology, 1999, Gaithersburg, MD.

22. NIST, "Certificate of Analysis. SRM 1649a: Urban Dust", National Institute of Standards and Technology, 2001, Gaithersburg, MD.

23. M. M. Schantz, Anal. Bioanal. Chem., 2006, 386, 1043. 